References:

[1] Hughes WT, et al.: N Engl J Med 1977;297:1419-26.

Disclosure of Interest: None declared

DOI: 10.1136/annrheumdis-2017-eular.4687

\section{AB0906 PYOGENIC SEPTIC ARTHRITIS: IS THERE A DIFFERENCE WHEN GERM IS NOT IDENTIFIED?}

${ }_{\text {H. Sahli }}{ }^{1}$, M. Sahli ${ }^{1}$, R. Tekaya ${ }^{2}$, O. Saidane ${ }^{2}$, R. Khalfallah ${ }^{1}$, I. Mahmoud ${ }^{2}$, L. Abdelmoula ${ }^{2}{ }^{1}$ Rheumatology Departement, Mohamed Taher Maamouri University Hospital, nabeul; ${ }^{2}$ Rheumatology Departement, Charles Nicolle Hospital, tunis, Tunisia

Background: Pyogenic septic arthritis (PSA), defined by the presence of living microorganisms in the affected joint, is a therapeutic emergency. Germ isolation is a primordial step in the diagnostic and therapeutic approach.

Objectives: The aim of this study was to study the differences between PSA with positive and negative bacteriology.

Methods: This is a retrospective study which included medical records of patients treated for PSA in a rheumatology department over seventeen years. The epidemioclinical and paraclinical data were recorded. We used the SPSS 11.5 for the statistical analysis to compare patients with (group 1) and without an isolated causative agent (group 2).

Results: We evaluated 49 patients with a diagnosis of PSA. They were $26(53.1 \%)$ men and $23(46.9 \%)$ women. The average age was $55+/-18.7$ years (ranging from 15 to 95 years). Comorbidities were observed in $31(63.3 \%)$ patients. The onset of symptoms was acute in $37(75.5 \%)$ patients and progressive in 12 $(24.5 \%)$ patients. The most common symptoms were joint pain and stiffness $(100 \%)$ and functional impotence $(87.8 \%)$. All patients were treated with double or triple antibiotics. Among the studied patients, $27(55.1 \%)$ had negative culture results. Statistical analysis used to compare cases with an isolated pathogen to those cases without an isolated pathogen, noted female predominance in group 2 but there was no statistically significant difference $(p=0.252)$. Patients in group 1 and group 2 had a comparable mean age $(p=0.08)$. Patients in both groups had comparable risk factors for PSA $(\mathrm{p}=0.549)$. Acute onset was more common in group $2(51.4 \%$ versus $48.6 \%)$ but without a significant difference $(p=0.507)$. Biological inflammatory syndrome was more frequent in group 2 but with no statistically significant difference $(p=0.235)$. The study of the appearance of the synovial fluid did not demonstrate a statistically significant difference between the two groups $(p=0.125)$. The abnormalities of standard $x$-rays were similar in both groups $(45.2 \%$ in group 1 versus $54.8 \%$ in group $2,(p=1))$. The statistical study of all other variables didn't show differences between the two groups.

Conclusions: PSA was not associated with major differences if the germ was or not isolated.

Disclosure of Interest: None declared

DOI: 10.1136/annrheumdis-2017-eular.6187

\section{AB0907 CONTRIBUTION OF IMAGING IN THE DIAGNOSIS OF INFECTIOUS SPONDYLODISCITIS}

H. Sahli ${ }^{1}$, A. Bachali ${ }^{1}$, R. Tekaya ${ }^{2}$, I. Mahmoud ${ }^{2}$, O. Saidane ${ }^{2}$, L. Abdelmoula ${ }^{2}$. ${ }^{1}$ Rheumatology Department, Mohamed Taher Maamouri University Hospital, nabeul; ${ }^{2}$ Rheumatology Department, Charles Nicolle hospital, tunis, Tunisia

Background: Infectious spondylodiscitisis represents a diagnostic and therapeutic emergency. Imaging is fundamental in the management of the disease.

Objectives: The aim of this study is to analyze the contribution of imaging in the diagnosis of infectious spondylodiscitis.

Methods: This is a retrospective study which included medical records of patients treated for psoas abcess during the twelve past years [2006-2016]. Epidemiologic, clinical, and imaging data (Standard X ray, Computed tomography (CT), magnetic resonance imaging (MRI)) were recorded and analysed.

Results: Ninety patients were included in this study. The average age was 55 years [16-86] with an even distribution between males and females. Mean symptom duration was of 4 months. The most frequently isolated pathogen was Mycobacterium tuberculosis $(63.3 \%)$, followed by pyogenic germs $(21.2 \%)$ and Brucella (15.5\%). Standard X ray were pathological in $89 \%$ of cases: showed narrowing of intervertebral space $(72.2 \%)$, endplate destruction $(42.2 \%)$, erosions of vertebra $(13.3 \%)$, opacity $(12.2 \%)$, vertebral fracture $(10 \%)$, paravertebral spindle $(5.5 \%)$ and posterior archlysis lesion (2.2\%). Standard radiographswere normal in 12 cases and in 1 case, spinal CT showed vertebral destruction wirh " mirror-image ". Spinal MRI, performed in the remaining 11 cases, confirmed the diagnosis in all cases and showed paravertebral collections $(n=3)$, epiduritis $(n=3)$, psoas abscess $(n=2)$, microabscess $(n=1)$ and spinal compression $(n=1)$. In case of posterior archlysis lesion and vertebral fracture, MRI confirmed the diagnosis by showing paravertebral collections.

Conclusions: Management of infectious spondylodiscitis has benefited from advancements in imaging allowing an early diagnosis and treatment.

Disclosure of Interest: None declared

DOI: 10.1136/annrheumdis-2017-eular.2770

\section{AB0908 BIOLOGICAL AND RADIOGRAPHIC FINDINGS IMPACT ON GERM IDENTIFICATION DURING SEPTIC ARTHRITIS}

H. Sahli ${ }^{1}$, M. Sahli ${ }^{2}$, R. Tekaya ${ }^{2}$, R. Khalfallah ${ }^{1}$, O. Saidane ${ }^{2}$, I. Mahmoud $^{2}$, L. Abdelmoula ${ }^{2} .{ }^{1}$ Rheumatology Departement, Mohamed Taher Maamouri University Hospital, nabeul; ${ }^{2}$ Rheumatology Departement, Charles Nicolle Hospital, tunis, Tunisia

Background: Septic arthritis may cause damage and inflammation in short period of time. The germ determination must be the first objective to allow targeted treatment. Bacteriological tests remain negative in $7-35 \%$ of cases of septic arthritis.

Objectives: The aim of this study was to determine the impact of biological and radiographic findings on germ identification during septic arthritis.

Methods: This a retrospective study which included medical records of patients treated for septic arthritis during the seventeen past years. Epidemiologic, clinical, biologic, bacteriologic and therapeutic data were recorded and analysed. We made a comparison between patients who had a germ identified (Group 1) with whom who hadn't (Group 2).

Results: Fifty nine patients with septic arthritis were included in this study. The mean age of the patients was $54.6 \pm 19$ years and a sex ratio (F/M) of 0.9 . Causative agents were isolated in 27 patients (45.7\%). Biological data showed leukocytosis in $25(42.4 \%)$ patients. Mean leukocyte count was $10673 \pm 5003$. Leukopenia was noted in 1 case. One patient had neutropenia. Lymphopenia was observed in 4 patients (6.7\%). Two patients had hyperlymphocytosis. Anemia, mainly of the inflammatory type, was noted in 47 cases $(79.66 \%)$. The mean Creactive protein (CRP) was $150.6 \pm 106$, and the mean erythrocyte sedimentation rate (ESR) was 104.9. Twenty three patients $(38.9 \%)$ had other perturbations of the biological balance: cholestasis $(n=1)$, cytolysis $(n=4)$ and renal perturbation $(n=15)$. Radiological signs suggestive of septic arthritis were observed in 40 cases $(67.8 \%)$ : articular pinching $(28.8 \%)$, geodes and erosions $(14 \%)$, total destruction of the joint $(0.67 \%)$ or thickening $f$ the soft parts at the beginning (11.86\%). Ultrasound exam, performed in 22 cases, showed articular effusion $(n=15)$, synovial thickening $(n=8)$, a soft tissue collection $(n=3)$, and periarticular erosion $(n=2)$. CT, performed in 6 patients, was normal in one case. The abnormalities noted were: collection of soft parts $(n=2)$, joint effusion $(n=2)$, bone demineralization $(n=1)$, bone erosion $(n=1)$ and osteochondritis $(n=1)$. MRI, performed in 2 patients, was pathological in both cases and showed synovitis and cortical erosion with medullary edema. The comparison of the 2 groups according to germ identification showed that biological inflammatory syndrome was more frequent in group $2(100 \%$ versus $96.8 \%)$ but without a statistically significant difference $(\mathrm{p}=0.346)$. Mean value of CRP and ESR were comparable in the two groups $(p=0.65$ and 0.19$)$. The mean value of hemoglobin was comparable in the two groups $(10.87$ versus $10.54 \mathrm{~g} / \mathrm{dl})(\mathrm{p}=0.566)$. It was similar about the blood count. Abnormalities of standard $x$-rays were similar in both groups $(70.4 \%$ in group 1 versus $65.5 \%$ in group 2$)(p=0.784)$. The most frequent radiological abnormality in the two groups was articular pinching (40.7\% in group 1 and $46.8 \%$ in group 2).

Conclusions: In our study, the biological and radiological data had not shown any impact on the identification of the germ.

Disclosure of Interest: None declared

DOI: 10.1136/annrheumdis-2017-eular.3835

\section{AB0909 SEPTIC PSEUDARTHROSIS OF THE HUMERUS TREATMENT USING ORTHFIX EXTERNAL FIXATION}

S. Daas ${ }^{1}$, H. Sahli ${ }^{2}$, M.A. Sbai ${ }^{1}$, M. Souissi ${ }^{1}$, A. Khorbi ${ }^{1} .{ }^{1}$ Orthopedic Departement; ${ }^{2}$ Rheumatology Departement, Mohamed Taher Maamouri University Hospital, nabeul, Tunisia

Background: The septic pseudarthrosis of the humerus is a very difficult process that poses a towfold challenge: the infection eradication while trying to get consolidation.

Objectives: The aim of this study was to analyze the results of the treatment of septic pseudarthritis of the humerus with Orthofix monolateral axial external fixator.

Methods: This is a retrospective study which included 17 medical records of patients treated for septic pseudarthritis of the humerus debridement and stabilization by Orthofix over a period of 7 years.

Results: They were 13 women and 4 men with a mean age 44 years. The fracture site was most often at the distal half of the humerus. The initial treatment of the fracture was pinning or intramedullar nailing. Surgical management of pseudoarthrosis was performed 3.5 months after the first surgical procedure. All cases had a bone debridement and stabilization with a monoplane Orthofix axial external side. Fifteen cases had also a bone graft. The mean period of stabilization was 7 months. Patients were evaluated clinically and radiologically each month. At the mean of three years of follow-up, we obtain osseous consolidation for all patients in the average of seven months. All patients underwent rehabilitation of the shoulder and elbow after treatment. The functional result were excellent results in $47 \%$ of cases, good results in $35,3 \%$ of cases and poor results in $17,7 \%$. The Quick DASH score average was $28 \pm 5$. The average of the elbow motion was $109^{\circ}$ of flexion with an average of $30^{\circ}$ of deficit in extension. The useful range of motion of the elbow was preserved in 14 patients. There was a shaft angulation under $20^{\circ}$ in 3 cases and over $20^{\circ}$ in 3 other cases. We noted 
in four cases a bone shortening consolidations of $2 \mathrm{~cm}$. We had a case of radial nerve neuraprexie which regressed spontaneously.

Conclusions: Orthofix is the method of choice for the treatment of septic pseudarthritis of the humerus.

Associate eradication of the germ antibiotic and steroid intake spongy it allows the consolidation of the bone. Furthermore, the monolateral axial external fixator is tolerated well and allows movement of the shoulder and elbow throughout the period of treatment.

Disclosure of Interest: None declared

DOI: 10.1136/annrheumdis-2017-eular.3852

\section{AB0910 INFECTIOUS SPONDYLODISCITIS IN THE SANITARY AREA OF TORRELAVEGA BETWEEN 2000 AND 2016: 62 CASES}

I. Morante Bolado ${ }^{1}$, M. Santos-Gómez ${ }^{1}$, I. Villa Blanco ${ }^{1}$, E. Aurrecoechea Aguinaga ${ }^{1}$, T. Ruiz Jimeno ${ }^{1}$, J. Calvo Alén ${ }^{2} \cdot{ }^{1}$ Rheumatology, Sierrallana Hospital, Torrelavega; ${ }^{2}$ Rheumatology, University Hospital of Araba, Vitoria, Spain

Objectives: To analyze the clinical characteristics, most frequent diagnostic methods and different treatments used in spondylodiscitis (SD) in our sanitary area. Methods: Descriptive and retrospective study of patients with the diagnose of infectious SD (clinical or microbiological) from 2000 to 2016. In each case we studied the presence of underlying diseases, an episode of infection in the previous 6 months, way of presentation, location, diagnostic methods, treatment and evolution, comparing among different etiologies.

Results: 62 patients were diagnosed of spondylodiscitis. 41 men (24-90 years: mean 71,7). 58 were pyogenic, 3 tuberculous (TBC) SD, and 1 candida. The patients with TBC were younger (mean age: $45.3 ; p<0.05$ ). An underlying disease was observed in 51 patients, specially Diabetes Mellitus (DM) (31\% of SD). 4 patients were Rheumatoid Arthritis patients. A previous episode of bacteriemia or a primary source of infection was identify in a $33 \%$ of the cases, obtaining a microbiological isolation in 47/62 (75.8\%) SD (43 bacterial, 3 TBC and 1 Candida). The most frequent pathogens were Gram $+\left(G_{+}\right)(50 \%$ of the total SD) being $\mathrm{S}$. aureus and $S$ epidermidis responsible of $21 / 62$ cases (33.8\%). In the $94 \%$ of SD caused by $\mathrm{G}_{+}$, hemocultures positive were obtained, in comparison to a $55 \%$ of SD caused by $G-(p=0.016)$.

The most frequent presentation symptoms were: lumbar pain $(95.1 \%)$, fever $(50 \%)$ and neurological deficit (18\%). Leucocytosis was present in only a third of the SD, observing an increase of ESR and CRP in the pyogen etiology ( $p$ no significative for low number of patients in SD group caused by TBC) and lower levels of hemoglobin, cholesterol and albumin. Lumbar area was affected in the $77 \%$ of SD ( $77 \%$ in $\mathrm{G}+$ and $50 \%$ in G-). In a $13 \%$ of patients, more than one intersomatic space was affected, being visible the presence of an abscess in $44 / 62$ cases $(71 \%)$. It was necessary surgical treatment in $7 / 44(16 \%) .5$ patients died due to pathology related to SD $(8 \%)$, without any correlation with a risk factor and other 5 presented a relapse in the subsequent months.

Conclusions:

- the bacterial SD are the predominant group, being DM the most frequent risk factor.

- The incidence of SD due to TBC and fungi is scarce in our environment, being absent the Brucella etiology.

- The G+ SD usually have a previous associated bacteriemia.

- The majority of the patients had pain in the presentation, but only half of them had associated fever.

- The most frequent location of SD was lumbar.

- We established a $8 \%$ of mortality rate in our sanitary area.

Disclosure of Interest: None declared

DOI: 10.1136/annrheumdis-2017-eular.4007

\section{AB0911 ACUTE RHEUMATIC FEVER CASE SERIES PRESENTING WITH ARTHRITIS IN ADULTS}

I. Dogan ${ }^{1}$, O.N. Koyun ${ }^{2} .{ }^{1}$ Rheumatology; ${ }^{2}$ Internal medicine, Hitit University Corum, CORUM, Turkey

Background: Acute rheumatic fever (ARF) is an inflammatory reaction to group A hemolytic streptococcus that emerging 2-3 weeks after infection; presenting with joint, cardiac, neurological and dermatological symptoms. The incidence is reported to be 0.5-3: 100.000 in developed countries and 20-100: 100.000 in developing countries. ${ }^{1}$ ARF is a common disease in Turkey. It is most common between the ages of 6 and 20 years. It is rare in adults and arthritis is common with carditis in adults. ${ }^{2}$

Objectives: Due to the ARF is rarer at adulthood, ARF-associated arthritis at adults has been reported as a case report series.

Methods: Five patients who were admitted to our rheumatology policlinic in a tertiary medical center located in Corum province, with early arthritis between 2014 and 2016 were diagnosed with ARF associated arthritis.

Results: The age of ARF associated arthritis patients ranged from 35 to 56 years (Mean age 45.6 years). Two of these patients were male and three were female. One patient has atrial fibrillation and coronary artery disease in other one as a comorbidity. All of patients had tonsillitis in the last 15 days. Two of the patients had a previous ARF story.
The results of the laboratory and the clinical findings are given in table:

\begin{tabular}{|c|c|c|c|c|c|c|}
\hline Patient & $\begin{array}{l}\text { Age/ } \\
\text { Gender }\end{array}$ & $\begin{array}{c}\text { Previous } \\
\text { ARF } \\
\text { Diagnosis }\end{array}$ & $\begin{array}{l}\text { Echocardiography } \\
\text { Findings }\end{array}$ & Arthritis & $\begin{array}{c}\text { Sydhenam chorea/ } \\
\text { subcutaneous } \\
\text { nodule/erythema } \\
\text { marginatum }\end{array}$ & $\begin{array}{c}\text { Anti- } \\
\text { STREPTOLYSINO } \\
\text { Antikoru } \\
(0-200 \mathrm{IU} / \mathrm{ml})\end{array}$ \\
\hline 1 & $35 / F$ & - & 2. MI & + & $-1-1-$ & 430 \\
\hline 2 & $42 / \mathrm{M}$ & + & mild MS & + & $-1-1-$ & 472 \\
\hline 3 & $42 / \mathrm{F}$ & - & 1-2. Al & + & $-/-/-$ & 500 \\
\hline 4 & $53 / F$ & - & $\begin{array}{l}\text { mild MS 2. Al, 2. TI } \\
\text { 2. } \mathrm{Al}, \text { 2. } \mathrm{TI}\end{array}$ & $\begin{array}{l}+ \\
+\end{array}$ & $-1-1-$ & 320 \\
\hline 5 & $56 / \mathrm{M}$ & + & 1. $\mathrm{Al}$ & + & $-1-1-$ & 456 \\
\hline
\end{tabular}

F: Female, M: Male, Al: Aortic valve insufficiency, MI: Mitral valve insufficiency, MS: Mitral valve stenosis, TI: Tiricuspit valve insufficiency.

Acute rheumatic fever associated arthritis was diagnosed according to Jones criteria due to migratory arthritis, carditis findings with Echocardiography, and ASO titer elevation. The ANA, anti-CCP, RF, and Brucella agglutination tests were negative. Non-steroidal anti-inflammatory drugs, oral methyl prednisolone $16 \mathrm{mg}$ per day and benzathidine penicillin G 1.2 million units per month were initiated as treatments. Methyl prednisolone dose was taperde gradually. In one patient using warfarin, depo peniciline i.m. was not given because it could be risky for hematoma. In another patient with coronary artery disease, methylprednisolone $4 \mathrm{mg}$ per day was started because coronary bypass was planned. Symptoms of all patients were improved after treatment.

Conclusions: Acute rheumatic fever associated arthritis is not a common condition in adult patients, and should be kept in mind with poststreptococcal reactive arthritis in arthritis developed after upper respiratory tract infections in adults.

References:

[1] Stollerman G.H. Rheumatogenic group A streptococci and the return of rheumatic fever, Adv. Intern. Med. 35 (1990) 1-25.

[2] Ben-Dov I. Acute rheumatic fever in adults over the age of 45 years: an analysis of 23 patients together with a review of the literature. Semin Arthritis Rheum. 1980 Nov; 10(2):100-10.

Disclosure of Interest: None declared

DOI: 10.1136/annrheumdis-2017-eular.2630

\section{AB0912 ASSESMENT OF CLINICAL AND RADIOLOGICAL PROGNOSTIC VARIABLES IN PATIENTS WITH SPONDYLODISCITIS}

J.J. Fragio Gil ${ }^{1}$, R. Gonzalez Mazarío ${ }^{1}$, M. Tasias Pitarch ${ }^{2}$, E. Calabuig Muñoz ${ }^{2}$, J. Ivorra Cortes ${ }^{1}$, C.M. Feced Olmos ${ }^{1}$, F.M. Ortiz-Sanjuan ${ }^{1}$,

E. Labrador Sánchez ${ }^{1}$, K. Arévalo Ruales ${ }^{1}$, E. Grau Garcia ${ }^{1}$, I. Chalmeta Verdejo ${ }^{1}$, L. Gonzalez Puig ${ }^{1}$, I. Martínez Cordellat ${ }^{1}$, R. Negueroles Albuixech ${ }^{1}$, C. Alcañiz Escandell ${ }^{1}$, J.E. Oller Rodriguez ${ }^{1}$, E. Vicens Bernabeu ${ }^{1}$, C. Nájera Herranz ${ }^{1}$, I. Cánovas Olmos ${ }^{1}$, D. Hervás Marín ${ }^{3}$, M. Salavert Lleti ${ }^{2}$, J.A. Román Ivorra ${ }^{1}$. ${ }^{1}$ Rheumatology Department; ${ }^{2}$ Infectious Disease Unit, HUP la Fe;

${ }^{3}$ Biostatistic Unit, IIS la Fe, Valencia, Spain

Background: Spondylodiscitis is an infectious disease of the intervertebral space, often caused by hematological spreading from a distance septic focus, especially Endocarditis. Because of its low incidence combined with an ambiguous symptoms, delay diagnosis and treatment of this condition, raising probability of an undesirable outcome.

Objectives: To identify poor prognosis variables in patients with Spondylodiscitis Methods: Observational retrospective study with non-quirurgic spondylodiscitis patients from 2010 to 2016 was performed. Demographic information, clinical history, laboratory test and radiological data were compiled from the clinical history management software. Statistical analysis was performed with the software R (version 3.3.2).

Results: We included 55 patients, with a mean age of 63.47 (16.11) years old. Males predominated (69\%). The average time with axial pain was $64.44(80.63)$ days. Mean length of hospital stay was 64.44 (80.63) days and readmission rate was $32.7 \%$. $20 \%$ of patients required further surgical procedures. Most of patients showed high CRP levels at their admission, with an average value of 112.97 (83.64) $\mathrm{mg} / \mathrm{L}$. Underlying endocarditis proportion was $16.4 \%$ and in this patients hospital stay was significative higher; nevertheless, it was not correlated with worse prognosis. $50 \%$ of patients showed vertebral destruction on MRI; $14.8 \%$ cord compression and $20.4 \%$ of patients developed neurological complications (7 of them paraparesis). Furthermore, vertebral destruction was statistically correlated with epidural abscess $(P=0.026)$. Isolation and microbiological identification in blood cultures was possible in $83.6 \%$ of patients. Most frequent bacteria was Gram positive (50.09\%), then Gram negative (18.2\%), mycobacteria (10,9\%) and fungi $(3.6 \%)$.

Conclusions: Delay in diagnosis is an important issue in Spondylodiscitis patients. Higher complications rates are mainly in relation to greater vertebral destruction. Underlying infectious endocarditis was described in a small proportion of patients in contrast to other studies. Presence of epidural abscess was also correlated with vertebral destruction, for this reason, patients with this finding should be more carefully follow-up.

Disclosure of Interest: None declared

DOI: 10.1136/annrheumdis-2017-eular.5891 